\title{
YENİ TİP EKSENEL AKILI ANAHTARLAMALI RELÜKTANS MOTOR MANYETİK ANALİZI VE TASARIMI
}

\author{
Yusuf ÖNER, Mehmet ÖZTÜRK \\ Pamukkale Üniversitesi, Mühendislik Fakültesi, Elektrik-Elektronik Müh. Böl., 20100 Denizli \\ voner@pauiedutr, sudriye@hotmailcom
}

(Geliş/Received: 22.09.2014; Kabul/Accepted: 03.08.2015)

\begin{abstract}
ÖZET
Bu çalışmada, Anahtarlamalı Relüktans Motorlar'da (ARM) yüksek tork ve geleneksel sargı yapısına göre düşük kaçak akıya sahip yeni bir ARM yapısı önerilmektedir. Geleneksel ARM'lerin aksine yeni yapıda sargılar doğrudan kutuplar üzerine sarılmamıştır. Sargılar üç katmanlı olarak birbirinden yalıtılmış şekilde ve rotora daha yakın bir yere yerleştirilmiş̧tir. Her faz sargısının iki yanında hareket edecek rotor kutupları oluşturulmuştur. Böylece faz sargılarında oluşacak akı eksenel olarak stator kutuplarından ve rotor kutuplarından devresini tamamlamaktadır. Bu özelliği ile geleneksel ARM'lerden ayrılmış ve eksenel akılı anahtarlamalı relüktans motor diye adlandırılmıştır (EA-ARM). Önerilen motor geometrisinin ANSYS Maxwell programında 3 boyutlu manyetik analizleri ve parametrik analizleri gerçekleştirilmiştir. Önerilen yapının prototipi geçekleştirilmiş ve deneysel sonuçlar ile simülasyon sonuçları karşılaştırılmıştır.
\end{abstract}

Anahtar Kelimeler: Anahtarlamalı relüktans motor, eksenel akılı anahtarlamalı relüktans motor, manyetik analiz, parametrik analiz

\section{THE MAGNETIC ANALYSIS AND DESIGN OF NEW TYPE AXIAL FLUX SWITCHED RELUCTANCE MOTOR}

\begin{abstract}
In this study, a new SRM structure with lower flux than high torque and conventional winding structure is proposed in Switched Reluctance Motors (SRM). Unlike conventional SRM motors, the winding are not directly rolled over poles in the new structure. Windings are placed to somewhere closer to rotor as three layered and isolated from one another. Rotor poles which will move on both sides of each phase winding have been created. Thus, the flux created in phase windings completes its circle from stator poles and rotor poles axially. With this feature, it is different from conventional SRMs and named as axial flux switched reluctance motor (AF-SRM). The 3D magnetic analysis and parametric analysis of the proposed motor geometry have been realized in ANSYS Maxwell program. The prototype of the proposed structure has been made and experimental results and simulation results have been compared.
\end{abstract}

Keywords: Switched reluctance motor, axial flux switched reluctance motor, magnetic analysis, parametric analysis

\section{GİRIŞ (INTRODUCTION)}

Anahtarlamalı relüktans motorlara (ARM) duyulan endüstriyel ilgi 1800 'lü yıllara dayanmaktadır [1]. Anahtarlamalı relüktans makinası ilk kez İskoçya'da 1838 yilında Dawidson tarafindan bir lokomotifi hareket ettirmek için kullanılmıştır [2, 3]. 1920’lerde ise C.L.Walker tarafindan bu günkü ARM'lerin özelliklerini taşıyan bir adım motoru icat edilmiştir. 1969 yılında S.A. Nasar klasik ARM'nin ilk temel özelliklerini ortaya koymuştur [4]. 1971 ve 1972 'de Bedford ve Hoft rotor konumuna eş zamanlı olarak stator sargı akımlarını anahtarlayarak bu günkü modern ARM'lerin şekillenmesini sağlamış ve ARM teknolojisinde yariiletken elemanlarn etkili bir şekilde kullanılmasında öncü olmuştur $[5,6]$.

Ayrıca rotor ve stator kutup geometrileri ve güç elektroniği çevirici yapıları üzerine de araştırmalarda bulunmuşlardır [7]. 1979 yilında Corda tarafindan 
0,75 kW gücündeki doğrusal ARM tasarımı gerçekleştirilerek motorun çalışma sonuçları elde edilmiştir [8]. Aynı yıl Ray ve Davis tarafindan az sayıda anahtarlama elemanı kullanılarak ARM'nin dönüştürücü devresi gerçekleştirildi. ARM tasarım öncülerinden sayılan Ray 1987 yılında Bass'ta 6/4 kutuplu 2,5 kW'lık bir motor tasarlamıştır. Ray bu çalışmasında ARM'u açık çevrim döngüsünde kontrol etmeye çalışmıştır [9].

1988 yllında Tohumcu ve Ertan tarafindan $1 \mathrm{~kW}$ gücünde $1500 \mathrm{~d} / \mathrm{d}$ 'lık bir ARM tasarlanmıştır [10]. Miller 1991 yılında ARM tasarımına bilgisayar destekli tasarım yaklaşımını getirerek optimum tasarım parametreleri üzerinde çalışmıştır [11]. 1991 yılında Miles tarafindan yüksek gerilimle çalışan 6/4 kutup oranlı bir ARM tasarlanmıştır [12]. 1993 yılında Materu ve Krishnan üretilen 6/4 kutup konfigürasyonlu prototip ARM'nin kayılarını bulmaya çalışmış, stator akım ile gerilim dalga şekilleri elde edilerek genel ifadeler üretilmeye çalışmıştır.

2000 yılında Khwaja M.Rahman tarafından üretilen 100 HP gücündeki ARM hibrit araçlar için kullanılmıştır. Tasarlanan ARM'nin hızlanma zamanının aynı güçteki asenkron motordan çok daha iyi olduğu gözlemlenmiştir [13].

1998 ile 2004 yılları arasında anahtarlamalı relüktans motor tasarımlarında ciddi gelişmeler kaydedilmiş, özellikle stator yapısında elde edilen tasarım optimizasyon sonuçları 2004 yılından sonra ortaya konan ilginç tasarımlara önderlik edecek nitelikler kazanmıştır [14-33].

2005 yilında Khor ve Sotudeh; 12/10 kutup yapısına ve iki faz enerjilendirme metoduna sahip asimetrik bir ARM sunmuştur [34]. Aynı yıl Ju Hwan ve Kwon ARM'ların en büyük problemlerinden biri olan tork dalgacıklarını azaltmak ve buna bağlı olarak çıkış gücünü arttırmak için yeni bir rotor kutup tasarımı geliştirmiştir [35]. Kutup şekillerinde yapılan değişikliklerin motor performansına olan etkilerine ait çalışmalar 2005 yılında Pandey ve Rajagopal ile devam etmiştir [36].

2005 y1lında Edrington, Krishnamurthy ve Fahimi tarafindan gerçekleştirilen kapsamlı çalışmada otomobil uygulamalarında kullanılan bipolar ARM ele alınmış ve kayda değer çıktılar elde edilmiştir [37]. ARM tasarımında elde edilen önemli gelişmeler bu motorların robotik uygulamalarda da yerini almasına neden olmuştur.

İlk önemli çalışma 2006 yılında Ashok ve Tesar tarafindan gerçekleştirilmiştir [38]. [39]'de ARM tasarıminda sonlu elemanlar metodunun etkili bir çalışması görülmektedir. $\mathrm{Bu}$ yıllarda otomotiv sektöründe yer almaya başlayan ARM doğrudan tahrikli dış rotorlu sistemlerde kullanılmaya başlanmıştır [40-42]. 2007 yılında Seok-Gyu Oh ve Krishnan iki fazlı ters-akı mantığına dayanan bir tasarım ile literatürdeki yerini almıştır [43]. Aynı yıl Krishnan önderliğinde gerçekleştirilen çalışmada " $E$ " tipi stator yapısına sahip iki fazlı bir ARM tasarlanmış ve deneysel sonuçları elde edilmiştir [44].

Aynı yıllarda ARM yavaş yavaş ev aletlerinde de yer edinmeye başlamıştır. 2007'de Ekram, Ravi, Rajagopal ve Mahajan tarafindan gerçekleştirilen çalışmada bir çırpıcı uygulaması görülmektedir [45].

2010'da Krishnamurthy önderliğinde gerçekleştirilen çalışmada rotor kutup sayısının stator kutup sayısından büyük olduğu bir ARM uygulaması gerçekleştirilmiş ve önemli sonuçlar elde edilmiştir. Uygulama; ARM'un kullanım çeşitliliğini desteklemesi açısından çok büyük bir öneme sahiptir [46]. 2010 yılında Ruba, Bentia ve Szabo gerçekleştirdikleri çalışmada kritik güvenlik katsayısı olan uygulamalarda sürme hassasiyeti çok yüksek olan anahtarlamalı relüktans motoru kullanarak bu motorun 5 farklı sargısında hata olmasına rağmen çalışmasını sürdürmesini öne sürerek motorun bu tarz uygulamalarda tercih edilme nedenlerini ortaya koymaya çalışmıştır [47].

Labak ve Kar 2010 yılında gerçekleştirdikleri pancake tip ARM uygulamasında motorun hafiflik, sicaklık adaptasyonu ve hata tolerans kapasitesine bağlı olarak performansına değinmiş ve etkili sonuçlar elde etmiştir [48].

\section{EA-ARM'UN YAPISI VE ÜRETIM SÜRECI (AF-SRM DESIGN AND PRODUCTION PROCESS)}

Eksenel akılı anahtarlamalı relüktans motorun (EAARM) yapısı geleneksel ARM'ların yapısından farklılık göstermektedir. Temel olarak silindirik stator sargısı, her biri iki parça halindeki üç rotor ve silindirik sargıların üzerine yerleştirilen stator kutuplarından meydana gelmektedir. Şekil 1'de bu kısımlar ve Tablo 1'de tasarlanan motorun boyutları gösterilmiştir.

Silindirik stator sargıları üzerine yerleştirilen stator kutupları ile rotor kutupları geleneksel ARM'lerde olduğu gibi alt alta gelmemektedir. Stator ve rotor kutupları karşılıklı gelmekte ve aynı eksene geldiklerinde en büyük endüktans oluşmaktadır. Şekil 1'de görüldüğü gibi geleneksel ARM yapısı ile tasarımı sunulan EA-ARM'un yapisı tamamen birbirinden farklıdır. Geleneksel ARM de akılar radyal bir şekilde dağılım yaparken yeni tasarlanan EA-ARM da ise eksenel bir akı dağılımı söz konusudur. 


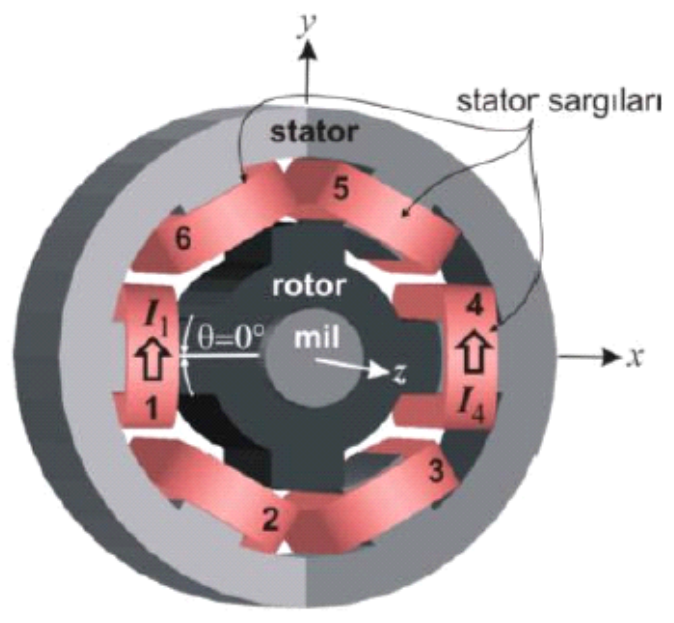

a

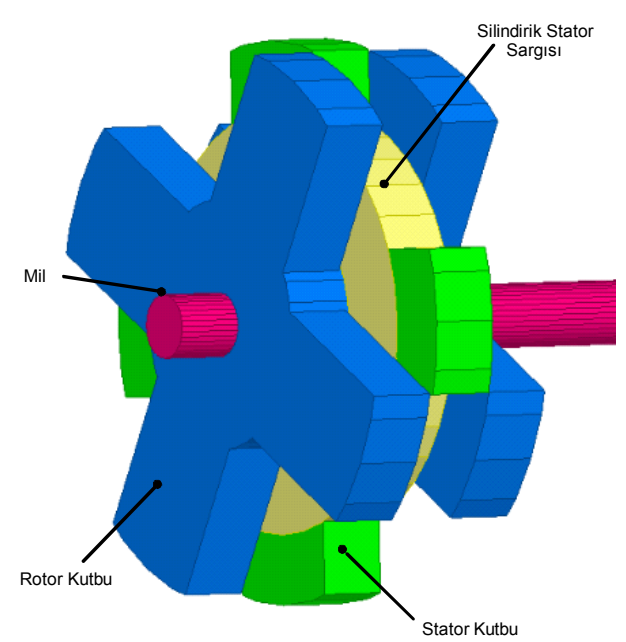

b

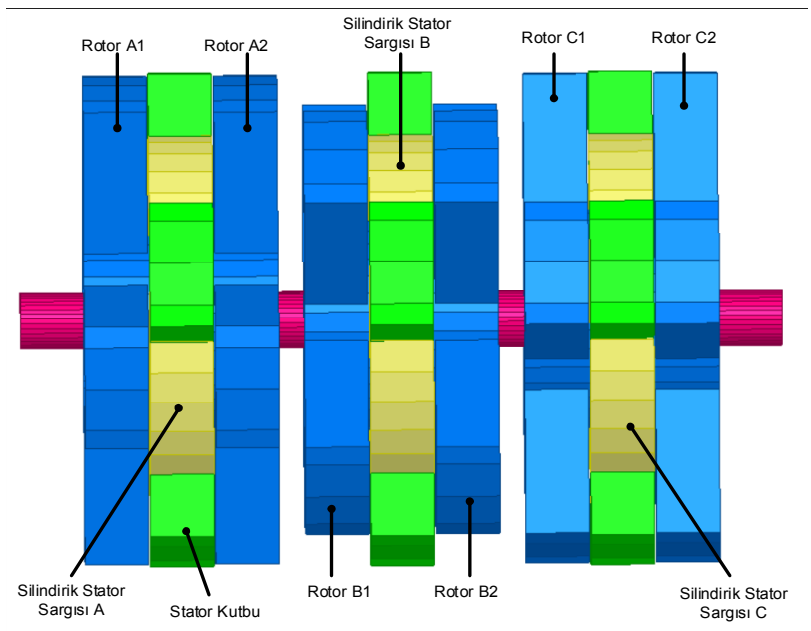

Şekil 1. (a) Geleneksel ARM yapısı [49], (b) EA-ARM 1 fazının yapısı (c) EA-ARM yapısı (( a) Traditional SRM structure, (b) The structure of the AF-SRM 1 Phase, (c) AF-SRM Structure)

Ayrica geleneksel ARM de rotor kutupları aynı hizadadır aksine EA-ARM da ise rotor kutupları birbirinden $30^{\circ}$ farklı açılarda yerleştirilmiştir. Rotor kutupları üç katmandan oluşmakta olup her bir katman arasında $30^{\circ}$ lik bir kaydırma açısı mevcuttur. Böylece $30^{\circ}$ lik bir açı yapan rotor kutbunun bir katmanı stator kutbundan kurtulup diğer rotor kutbunun stator kutbu karşısına gelmesi sağlanmıştır. Motor geometrik ölçüleri Hossein T. ve arkadaşlarının makalesinden esinlenerek alınmış ve bu ölçülerde tasarlanan motor modeli üzerinde rotor ve stator kutup yaylarının ölçüleri üzerinde parametrik analizler yapılmıştır.[50]. EA-ARM'un rotor kutupları mile birbirinden $30^{\circ}$ lik geometrik açı ile yerleştirilmişsir. Stator sargısı üzerine yerleştirilen stator kutuplarının da boyutları merkezle $30^{\circ}$ lik bir açıyı gören yay uzunluğunda tasarlanmıştır. Böylece rotor ve stator kutupları tam olarak üst üste çakışma meydana getirmektedirler.
Tablo 1: Tasarımı yapılan EA-ARM'ye ait ölçüler (Design by the AF-SRM measurements )

\begin{tabular}{|c|c|}
\hline Mil çapı (Dsh) & $9 \mathrm{~mm}$ \\
\hline $\begin{array}{c}\text { Rotor iç çapı } \\
\text { (Dri ) }\end{array}$ & $35,4 \mathrm{~mm}$ \\
\hline $\begin{array}{c}\text { Rotor dis çapı } \\
\text { (Dro) }\end{array}$ & $80 \mathrm{~mm}$ \\
\hline $\begin{array}{c}\text { Stator kutup } \\
\text { derinliği }(D)\end{array}$ & $10 \mathrm{~mm}$ \\
\hline $\begin{array}{c}\text { Paket uzunlugu } \\
(\text { Lstk) }\end{array}$ & $100 \mathrm{~mm}$ \\
\hline Hava aralıgı $(l g)$ & $0,3 \mathrm{~mm}$ \\
\hline $\begin{array}{c}\text { Stator kutup } \\
\text { yayı }(\beta s)\end{array}$ & $10^{\circ}-30^{\circ}$ \\
\hline $\begin{array}{c}\text { Rotor kutup } \\
\text { yayı }(\beta r)\end{array}$ & $10^{\circ}-30^{\circ}$ \\
\hline
\end{tabular}


Stator kutup yayı $(\beta \mathrm{s})$ ile rotor kutup yayı $(\beta \mathrm{r})$ parametrik olarak $10^{\circ}-30^{\circ}$ arasında analiz yapılmıș ve sonuç olarak her ikisinin de $29.9^{\circ}$ yay açısı olduğu durumda en yüksek tork değerleri elde edilmiştir. Uygulamada stator kutup yayı ve rotor kutup yayları açısı $29.9^{\circ}$ olarak seçilmiştir.

Tasarlanan motorun stator kutupları Steel 1010 malzemeden seçilmiştir. Bunun nedeni artık mıknatıslığın minimum seviyede istenmesidir. Kutuplar Steel 1010 malzemeden CNC'de işlenerek imal edilmiştir. Motor stator kutupları, sargıların üzerine polyester ile yerleştirilen kutuplar vasıtası ile sağlanmıştır.

Böylece manyetik etkilerde stator kutuplarının hareket etmemesi sağlanmıştır. Motor stator kutupları ve $1 \mathrm{faz}$ sargısı üzerine yerleştirilişi şekil 2 'de gösterilmiştir.

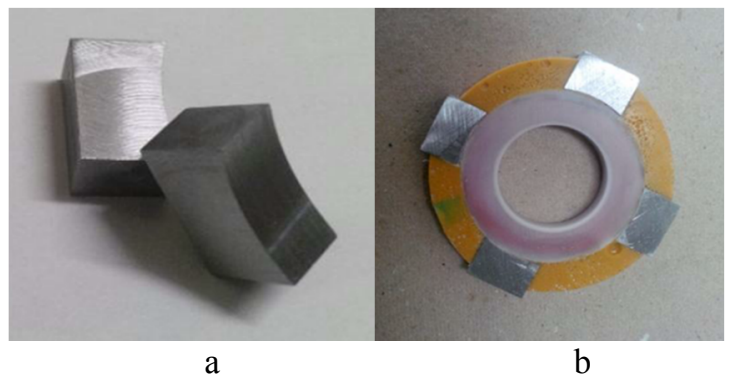

Şekil 2. (a) Stator kutupları, (b) Bobin ve stator kutuplarının polyestere gömülmüş hali, (( a) Stator Poles, (b) Coil and stator joined with polyester ))

Stator sargilar1 1000 sipir $0.50 \mathrm{~mm}^{2}$ kesitli emaye bakır telden sarılmıştır. Sargının yerleştiriliş şekline ve akım yönüne göre sargının oluşturduğu akılar eksenel şekilde stator kutuplarından rotor kutuplarına doğru dolaşmaktadır. Böylece motorun dönmesi için gerekli momenti oluşturmaktadır.

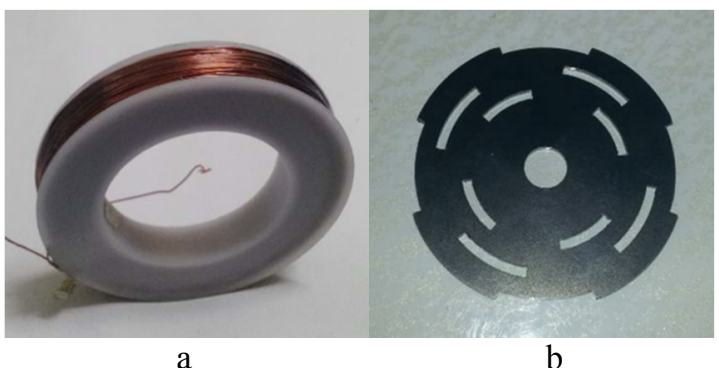

Şekil 3. a) 1 Faz stator sargisı b) Enkoder ( a) 1 Phase stator coil, b) Encoder )

Motorun konum bilgisini alıp sürücü devrede tetikleme sinyallerini oluşturabilmek için motor miline bağlı bir enkoder tasarlanmıştır. Şekil 3'de stator sargısı, ve enkoder gösterilmiştir. EA-ARM genel görünümü Şekil 4'de gösterilmiştir.

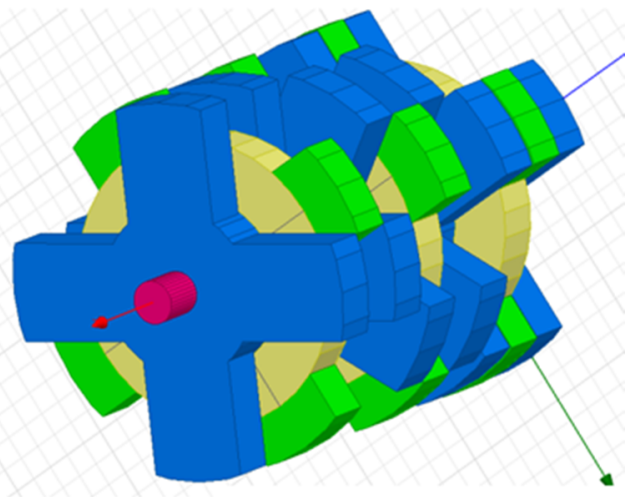

a

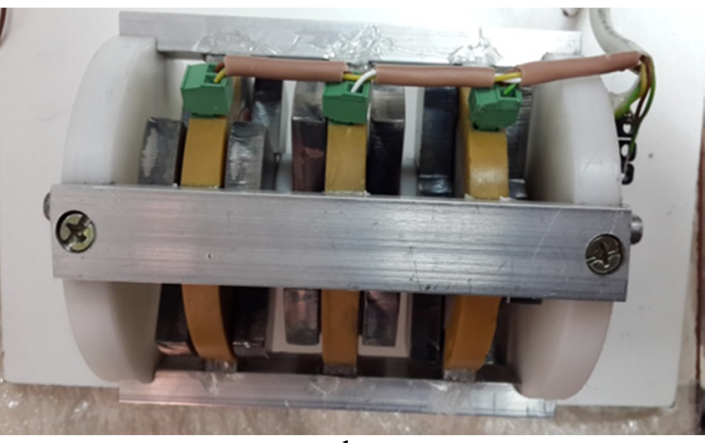

b

Şekil 4. EA-ARM analizi yapılan model ve uygulama görüntüsü (AF-SRM analysis of the model and application image)

\section{ARM'NIN EŞDEĞER DEVRESİ (EQUIVALENT CIRCUIT OF THE SRM)}

Tasarlanan ARM'de akı diğer geleneksel ARM'lerde olduğu gibi stator kutbu ucundan çıkarak hava aralığına ve daha sonra rotor kutbuna geçmemektedir. Burada akı sargidan stator kutbuna oradan hava yolu ile rotor kutbunun yan yüzeyine geçmektedir. Dolayısı ile akının geçebileceği akı yolu genişletilmiştir. Böylece stator ile rotor arasındaki çekim kuvveti arttırılmış olur. Şekil 5'de tasarlanan EA-ARM'deki akı yolu gösterilmiştir.
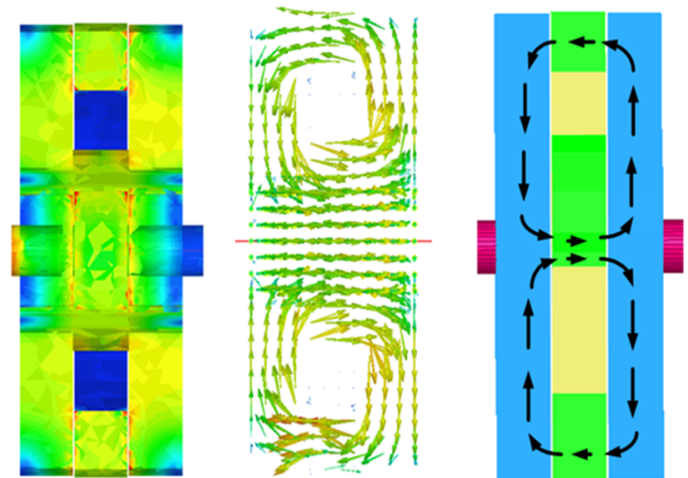

Şekil 5. EA-ARM'deki akı yolu ve vektörel gösterilişi (Flux path and vectorial presentation in the AF-SRM) 
ARM'lerin çalışma prensibi relüktans kuvvetine dayanmakta ve serbest hareketli, çıkık yapılı rotorun, bulunduğu manyetik devre içerisindeki akının, en kolay yol bulabileceği en küçük relüktans konumuna kadar kuvvet uygulanarak çekilmesi şeklinde gerçekleşmektedir. Şekil 6'da ARM'nin tek fazına ait eşdeğer devre gösterilmektedir.

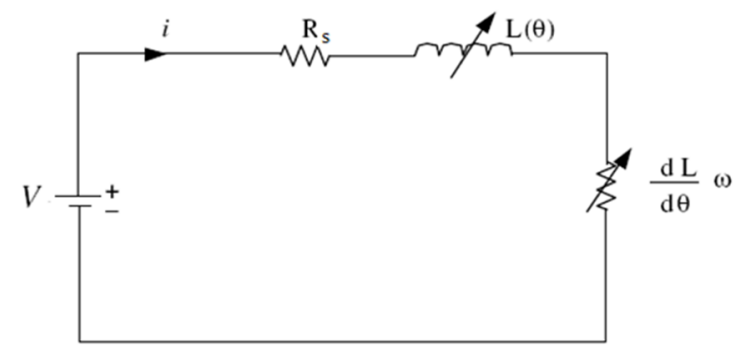

Şekil 6. ARM'nin tek fazına ait elektriksel eşdeğer devre (Electrical equivalent circuit of the single phase SRM )

Şekil 6'da verilen devrede $\mathrm{R}_{\mathrm{s}}$, her bir faz için stator sargısına ait direnci ve $\mathrm{L}$ endüktans değerini temsil etmektedir.

Burada, her bir faza uygulanmakta olan gerilim değeri eşitlik (1)'deki gibi verilebilir.

$v=R_{s} i+\frac{d \lambda(\theta, i)}{d t}$

ve

$\lambda=L(\theta, i) i$

Şeklinde ifade edilebilir. Giriş gücü ise eşitlik 3'de verildiği gibi ifade edilebilir.

$P_{i}=v i=R_{s} i^{2}+i^{2} \frac{d L(\theta, i)}{d t}+L(\theta, i) i \frac{d i}{d t}$

Burada;

$\frac{d}{d t}\left(\frac{1}{2} L(\theta, i) i^{2}\right)=L(\theta, i) i \frac{d i}{d t}+\frac{1}{2} i^{2} \frac{d l(\theta, i)}{d t}$

Eşitliği yazılabilir ve dolayısıyla giriş gücü,

$P_{i}=R_{s} i^{2}+\frac{d}{d t}\left(\frac{1}{2} L(\theta, i) i^{2}\right)+\frac{1}{2} i^{2} \frac{d L(\theta, i)}{d t}$

şeklinde ifade edilir.

Eşlitlik (5)'den de açıkça görüleceği üzere giriş gücü, $R_{s} i^{2}$ ifadesi ile verilen sargı kayı gücü, $p\left[L(\theta, i) i^{2} /\right.$ $2)$ ] ifadesi ile verilen alan enerjinin değişim oranı ve $\left[i^{2} p L(\theta, i)\right] / 2$ ifadesi ile verilen hava aralığ gücünün toplamından oluşmaktadır

Hava aralığı gücü için zaman ifadesinde rotor pozisyonu ve hız terimleri yerine koyulacak olursa,
$T_{e}=\frac{\theta}{w_{m}}$

ve dolayısıyla da,

$P_{a g}=\frac{1}{2} i^{2} \frac{d l(\theta, i)}{d t}=\frac{1}{2} i^{2} \frac{d L(\theta, i)}{d \theta} \frac{d \theta}{d t}$

$P_{a g}=\frac{1}{2} i^{2} \frac{d L(\theta, i)}{d \theta} w_{m}$

ifadesi elde edilir.

Hava aralığı gücü elektromanyetik moment ve hıza bağlı olarak,

$P_{a g}=T_{e} w_{m}$

olduğundan motora ait moment,

$T_{e}=\frac{1}{2} i^{2} \frac{d L(\theta, i)}{d \theta}$

şeklinde elde edilir. [11], [51]

\section{EA-ARM'NUN 3D MANYETIK ANALIZİ VE SONUÇLARI (AF-SRM 3D MAGNETIC ANALYSIS AND CONCLUSIONS)}

EA-ARM'nun manyetik analizleri üç boyutlu olarak Ansys Maxwell programında gerçekleştirilmiştir. Tasarlanan model üzerinde tranzient analizler yapılmıștır. Model oluşturulurken stator dıș çapının 4 katı ve stator paket uzunluğunun 4 katı büyüklüğünde bir bölgenin en diş kenar yüzeylerine Dirichlet sınır koşulu atanmıştır[52-53]. Yaklaşık \%1'lik bir çözüm hassasiyetinde, bölge içindeki sonlu elemanların [54] sayısı ortalama 232000'e karşılık gelmektedir.

Şekil 7'de tasarlanan modelin ağlara bölünmüş hali gösterilmiştir.

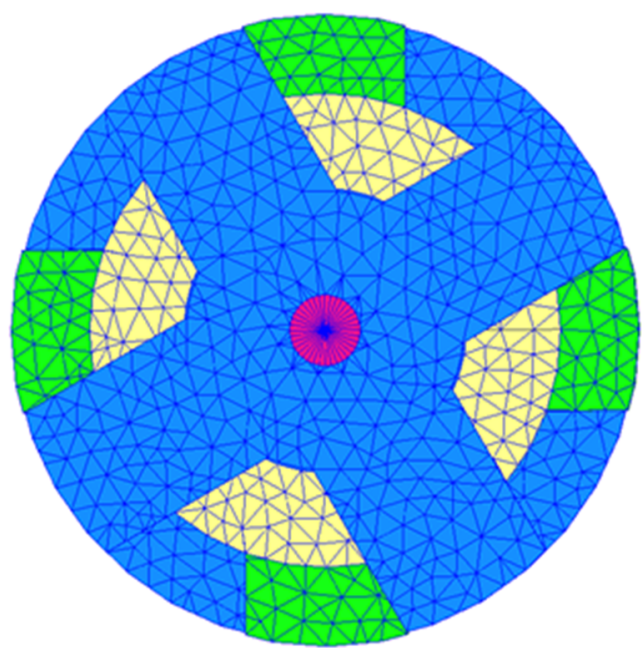

Şekil 7. EA-ARM'nin alan çözümü için gerekli olan ağ (mesh) yapısi. (AF-SRM required for site remediation network (mesh) structure) 


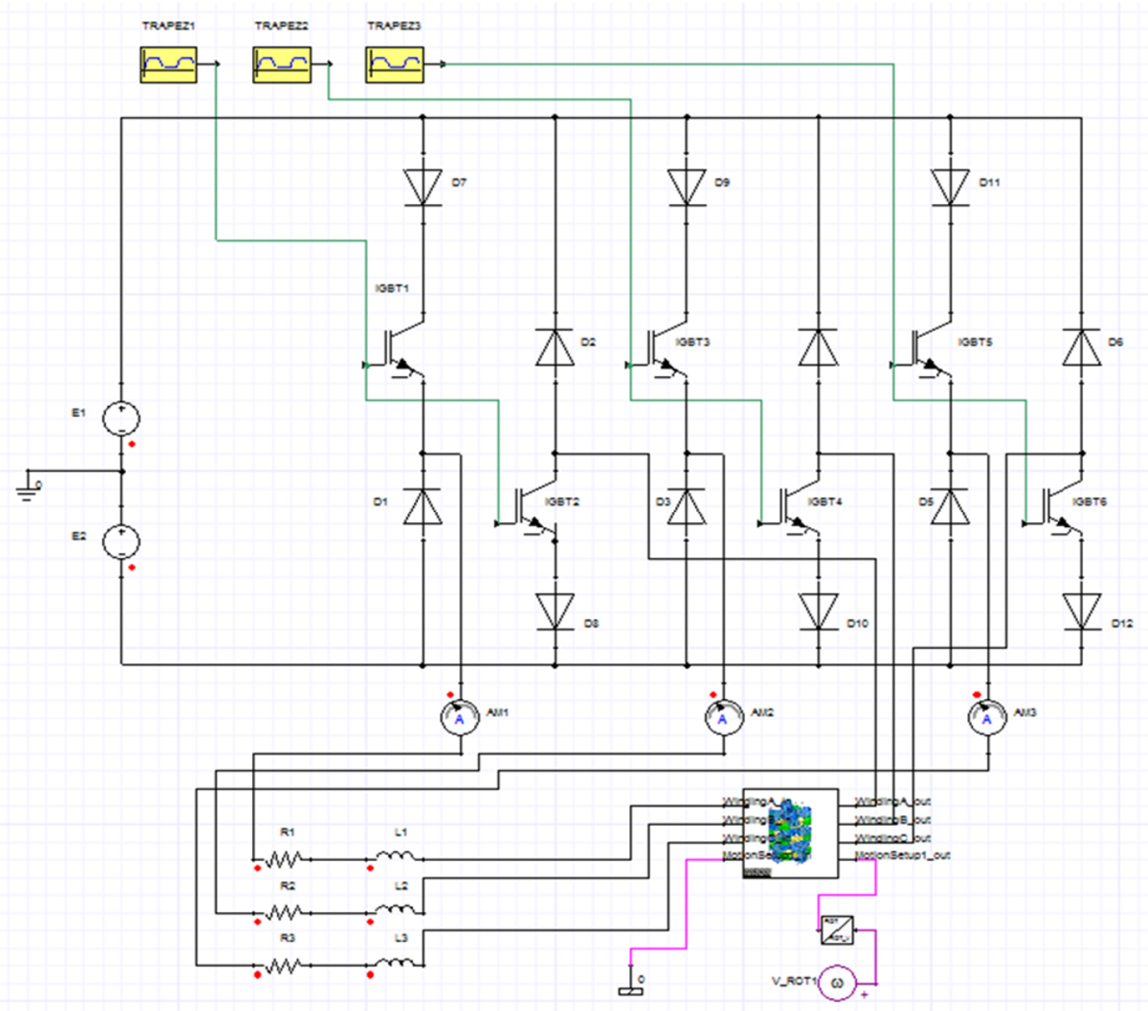

Şekil 8. EA-ARM'nin manyetik simülasyon için kullanılan sürücü devresi (AF-SRM drive circuit used for the magnetic simulation)

EA-ARM motorlar konum kontrolü ile anahtarlanabilen motorlardır. Yani motorun ilk konum bilgisi alındıktan sonra sargilara bir gerilim uygulanır. Manyetik simülasyonda tranzient analiz için şekil 8'deki simplorer programında çizilen anahtarlama devresi kullanılmıştır. Bu devre 3 boyutlu manyetik devre modelini kullanarak gerçeğe yakın bir analiz gerçekleştirmektedir. $\mathrm{Bu}$ devre incelenecek olursa konum bilgisi 3 boyutlu manyetik devreden alınarak anahtarlamalar yapılmaktadır.

Modelde, rotor ve stator için kullanılan manyetik malzeme Steel 1010 BH eğrisi şekil 9'da verilmiștir. Analitik hesaplamalarda manyetik malzemenin bağıl manyetik geçirgenliği ( $\mu \mathrm{r}$ ) sabit alınmıştır.

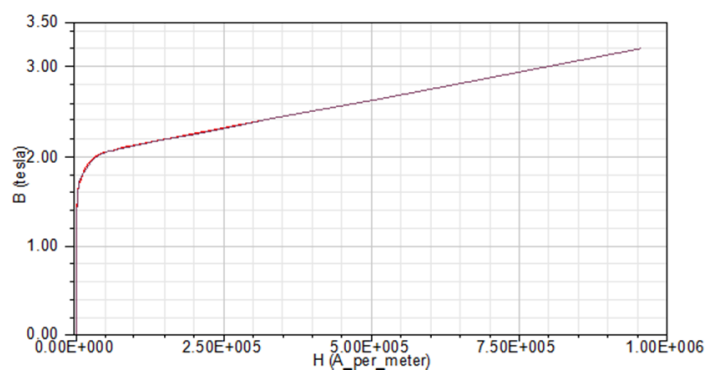

Şekil 9. Motor modelindeki stator ve rotor malzemesinin steel $1010 \mathrm{BH}$ eğrisi (Steel $1010 \mathrm{BH}$ curve of the motor stator and rotor material)

EA-ARM'un yapılan manyetik analizleri sonucunda farklı konumlardaki manyetik analiz sonuçları elde edilmiştir. Stator ve rotor kutupları arasında maksimum açıklığın bulunduğu $30^{\circ}$ lik durumdaki manyetik akı değerinin vektörel gösterilişi şekil 10'da verilmiştir.

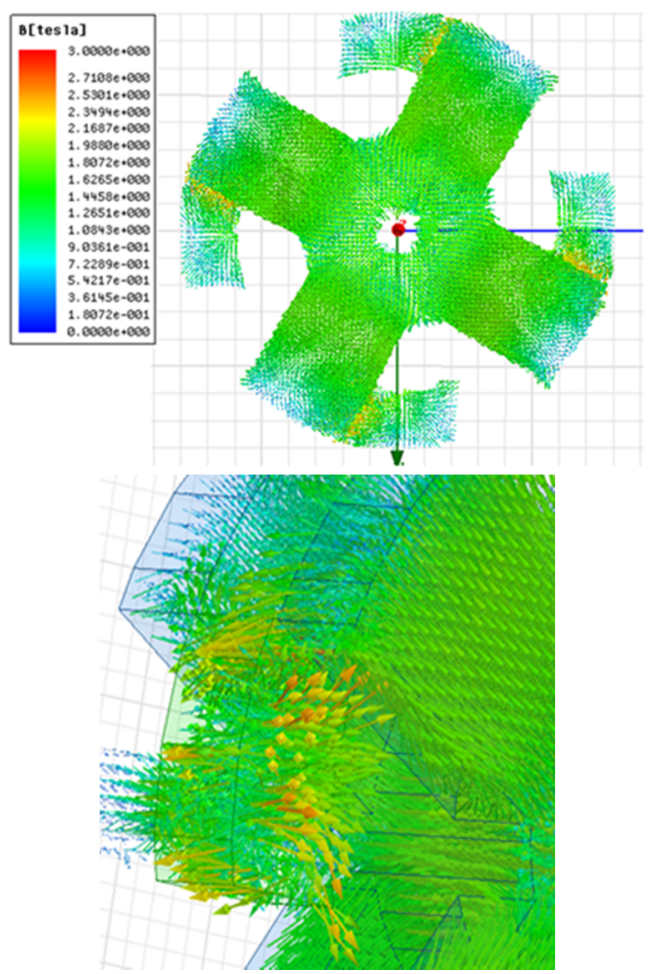

Şekil 10. Stator ve rotor kutupları arasında 300 lik açıdaki manyetik akı değerlerinin vektörel gösterilişi (Between the stator and rotor poles at an angle of 300 vector representation of the magnetic flux value) 
EA-ARM'un sargiları tasarlanan enkoder sayesinde tek tek yada tork dalgalanmalarını azaltmak için belirli açılarda birlikte tetiklenmektedir. Şekil 6'da gösterilen manyetik akı yolu manyetik analizler sonucunda rahatlıkla görülmektedir. Şekil 11'de tek bir sarg1 enerjili iken rotor, stator ve hava aralığındaki manyetik akı vektörel olarak gösterilmiştir. Şekil 11 a incelenecek olursa hava aralığında kaçak akıların yok denecek kadar az olduğu görülmektedir. EA-ARM'un yapılan analizleri sonucunda tork, endüktans, akı, akım ve gerilim eğrileri elde edilmiştir. Geleneksel ARM'lere benzer şekilde endüktas değişimi rotor ve stator konumuna bağlı olarak değişmektedir. Kutuplar birbirinden çok uzak pozisyonda ise endüktans en düşük değerde, kutuplar çakışık konuma geldiklerinde ise endüktans maksimum değere gelmektedir.

Şekil 12'de sarg1 endüktansları gösterilmiştir. Bu eğrideki minimum ve maksimum değerlere bakılarak sargilar enerjilendirilmektedir.
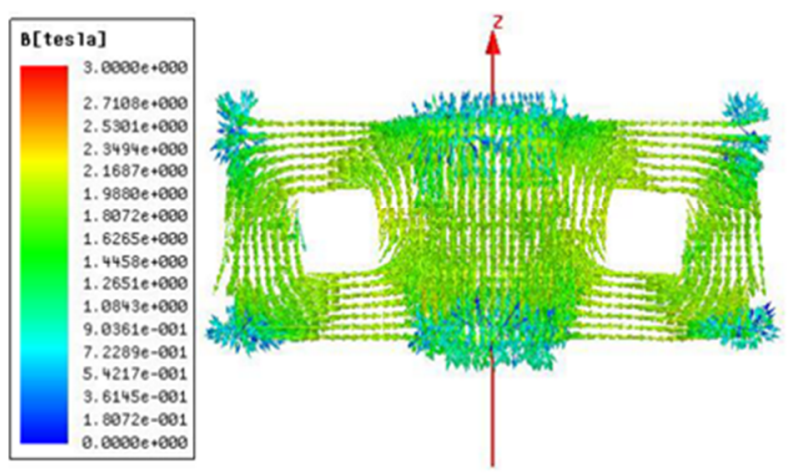

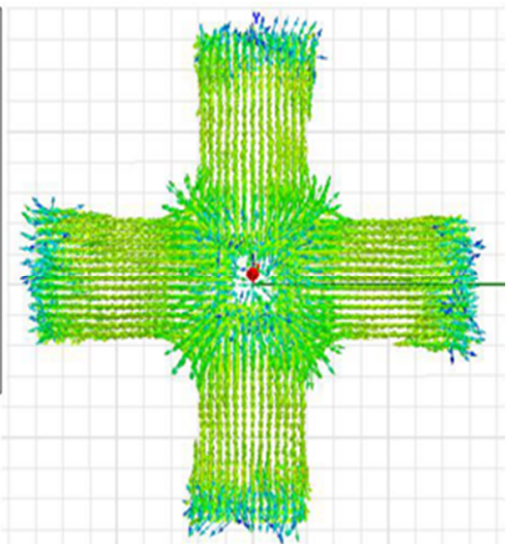

a

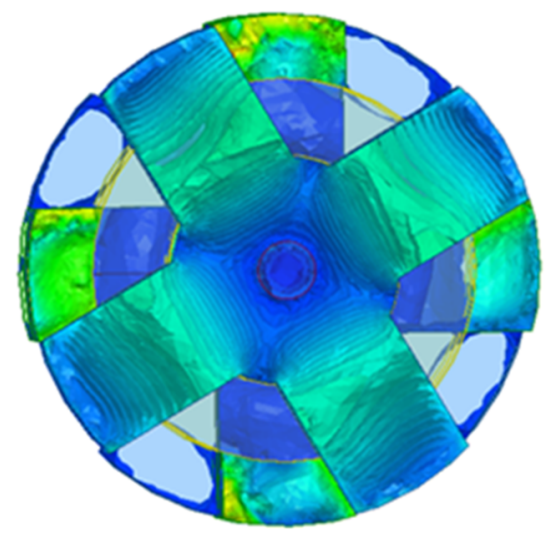

b

Şekil 11. Stator, rotor ve hava aralığında ki manyetik akı yolunun a) vektörel gösterilişi b) Manyetik akı çizgilerinin gösterilişis (Stator, rotor and air-gap magnetic flux path in a) the vector representation b) representation of the magnetic flux lines)

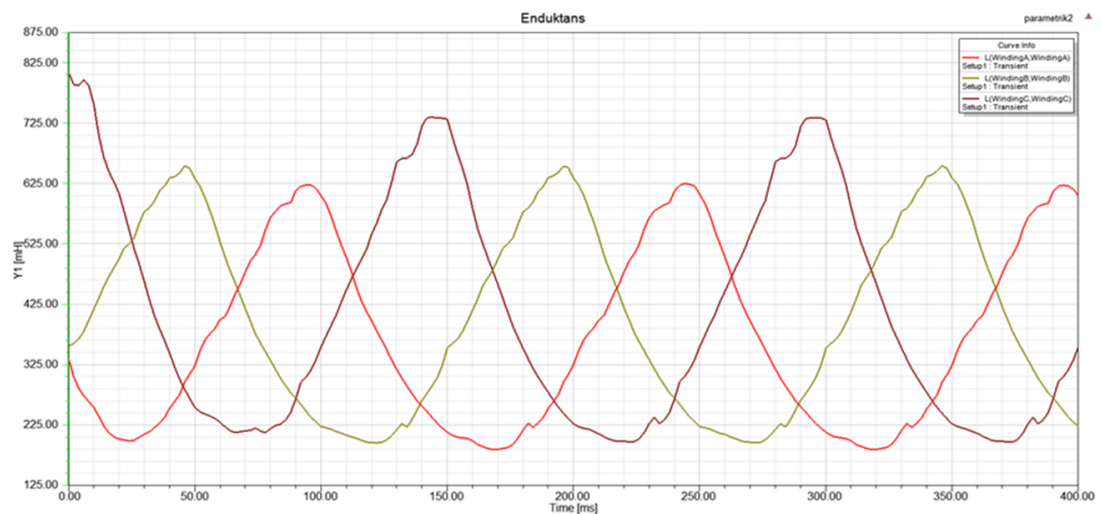

Şekil 12. EA-ARM'nin sarg1 endüktans eğrileri (AF-SRM winding inductance curves) 
Şekil 9'daki sürücü devre ile yapılan manyetik analiz sonucunda sargilar üzerinde indüklenen EMK değerleri Şekil 13'de gösterilmiştir. Motor sargılarının beslemesi Simplorer programında çizilen sürücü devrede elde edilen açısal hız konum bilgisine göre anahtarlar tetiklenerek sağlanmıştır.

Indüklenen gerilim eğrileri incelenecek olursa negatif değerlikli gerilimler sargılarda endüklenen zıt emk'lar olmakla birlikte kaynağa geri verilmektedir.

Şekil 14'de EA-ARM'nın sargılarına uygulanan gerilim sonucunda sargıların oluşturdukları akı değerleri görülmektedir. Motor sargılarının çekmiş olduğu akımlar Şekil 15'de Akım-zaman grafiği şeklinde gösterilmiştir. Konum bilgisine göre ilk sırada B sargisı sonra A sargısı ve en sonda ise C sarg1s1 enerjilendirilmektedir.

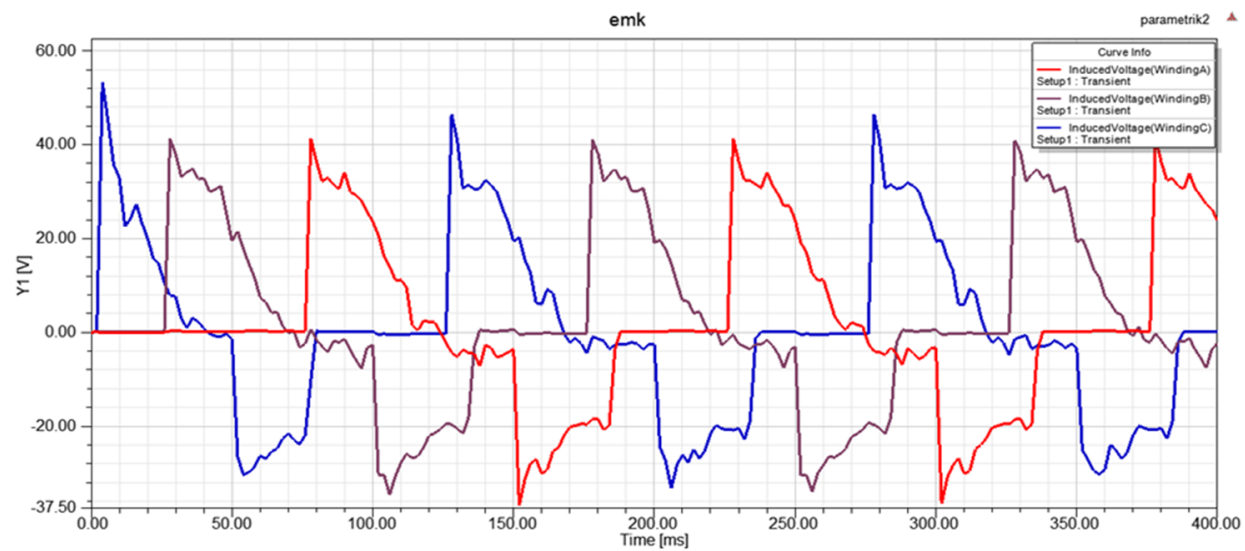

Şekil 13. Sargilar üzerinde indüklenen gerilim eğrileri (Induced voltage curves of the windings)

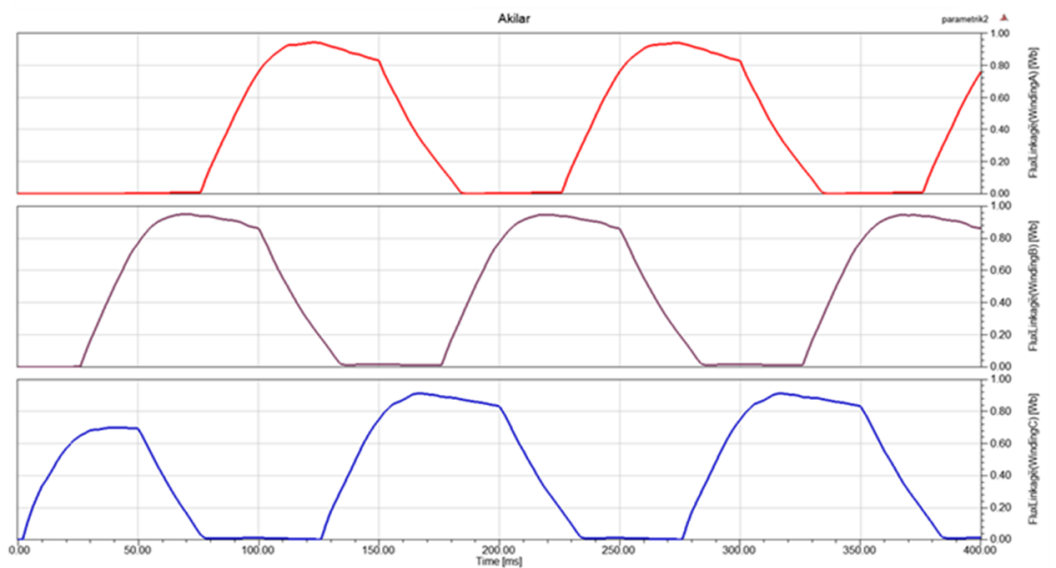

Şekil 14. EA-ARM'nın sargılarının oluşturdukları akı değerleri eğrileri (AF-SRM curves formed by the coil current values)

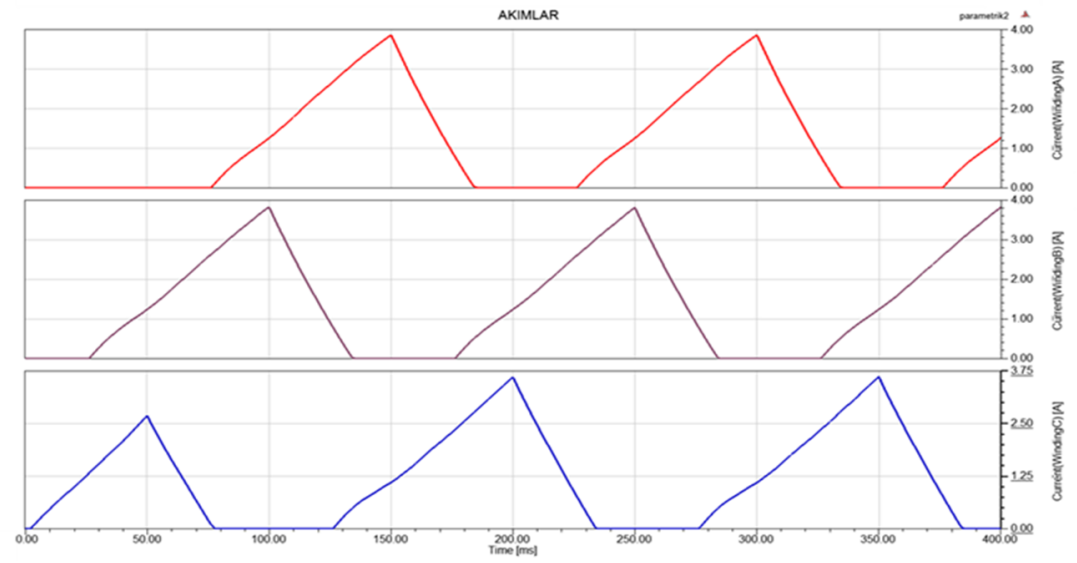

Şekil 15. EA-ARM'nın sarg1 akımları (AF-SRM winding currents) 


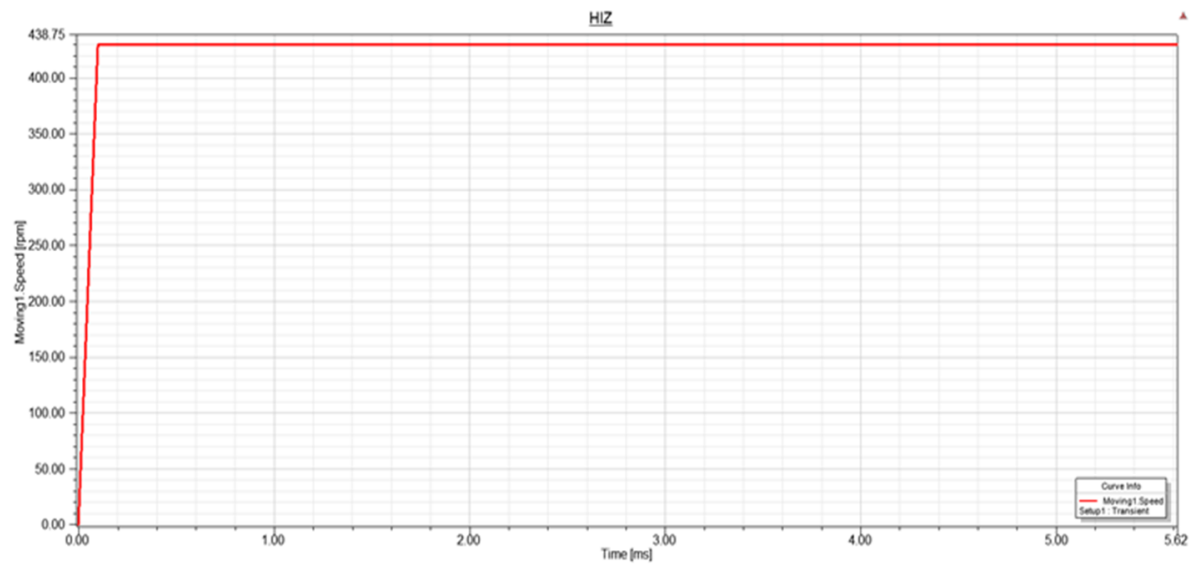

Şekil 16. EA-ARM'un hız-zaman grafiği (AF-SRM's speed-time curve)

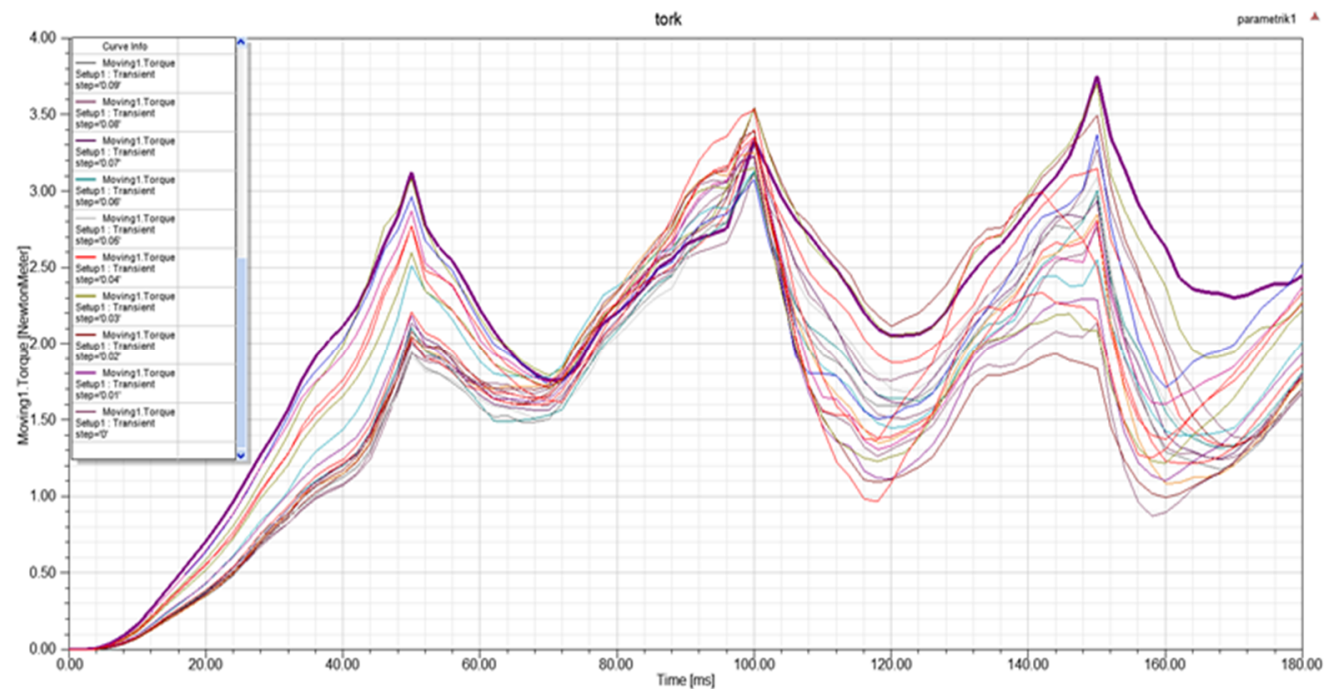

Şekil 17. Stator ve rotor kutup geometrisinin motor tork değerine etkileri (Effects of motor torque of the stator and rotor pole geometry)

EA-ARM sargılarının bu şekilde enerjilendirilmesi ile motor hızı çok kısa bir süre içerisinde $429.77 \mathrm{rpm}$ değere ulaşmakta ve burada sabit kalmaktadır. Şekil 16'da Hız-zaman grafiği verilmiştir.

EA-ARM'un tasarımı gerçekleştirilirken motor boyutları konusunda parametrik analizler gerçekleştirilmiş olup parametrik analizler rotor ve stator kutup ölçülerinin optimizasyonu şeklinde yapılmıştır. En uygun tork değerini verebilecek rotor ve stator kutup kombinasyonları denenmiş ve parametrik analizler gerçekleştirilmiştir. Analiz yapılırken gerilim, hız, yük gibi değişkenler sabit tutulmuş sadece rotor ve stator geometrisi değiştirilerek bir parametrik analiz gerçekleştirilmiştir. Şekil 17'de parametrik analizlerin tork değeri üzerindeki etkileri görülmektedir.

Şekil 17 incelenecek olursa bu şekilde koyu renkle gösterilen tork değeri ve bu torkun üretildiği geometrik yapı motor stator ve rotor geometrik ölçüsü olarak seçilmiştir. Şekilde görüldüğü gibi motor tarafindan üretilen tork değeri tepe değerlerde maksimuma çıkmış ancak çok fazla miktarda minimum değere inmemiştir. Yani tork dalgalanması diğer yapılara göre azdır.

Tablo 2'de parametrik analiz sonuçlarına göre tork tepe değerleri ve ortalama değerleri verilmiştir.

Tablo 2. Motor stator ve rotor geometrisine göre maksimum ve ortalama tork (Maximum and average torque according to the motor stator and rotor geometry)

\begin{tabular}{|c|ccc|}
\hline & step & $\begin{array}{c}\text { pk2pk(Moving1.Torque) } \\
\text { Setup1. Transient }\end{array}$ & $\begin{array}{c}\text { mean(Moving1. Torque) } \\
\text { Setup1. Transient }\end{array}$ \\
\hline 1 & 0.000000 & 3.266380 & 2.069687 \\
\hline 2 & 0.010000 & 3.754500 & 2.518800 \\
\hline 3 & 0.020000 & 3.546030 & 2.256717 \\
\hline 4 & 0.030000 & 3.699250 & 2.490790 \\
\hline 5 & 0.040000 & 3.353700 & 2.121436 \\
\hline 6 & 0.050000 & 3.190920 & 2.002862 \\
7 & 0.060000 & 3.128460 & 1.968530 \\
\hline 8 & 0.070000 & 3.306330 & 2.023989 \\
\hline 9 & 0.080000 & 3.326770 & 1.946321 \\
10 & 0.090000 & 3.118810 & 1.927719 \\
11 & 0.100000 & 3.131320 & 2.028362 \\
12 & 0.110000 & 3.366860 & 2.242786 \\
\hline 13 & 0.120000 & 3.398880 & 1.967932 \\
\hline 14 & 0.130000 & 3.251870 & 1.955834 \\
15 & 0.140000 & 3.343540 & 2.141210 \\
16 & 0.150000 & 3.219050 & 1.824826 \\
17 & 0.160000 & 3.229340 & 1.859786 \\
18 & 0.170000 & 3.390860 & 1.798665 \\
19 & 0.180000 & 3.149660 & 1.979732 \\
\hline 20 & 0.190000 & 3.529830 & 2.220219 \\
\hline 21 & 0.200000 & 3.352220 & 2.024417 \\
\hline
\end{tabular}




\section{PROTOTIP VE DENEYSEL SONUÇLAR (PROTOTYPE AND EXPERIMENTAL RESULTS)}

Birbirinden yalıtımlı olan A-B-C sargıları, tasarlanan enkoder ile $\mathrm{H} 21 \mathrm{~A} 1$ fototransistörden konum bilgisi alınarak enerjilendirilir. Enkodere bağlı olan fototransistör konum bilgisi sinyalleri Şekil 18'de gösterilmiştir.

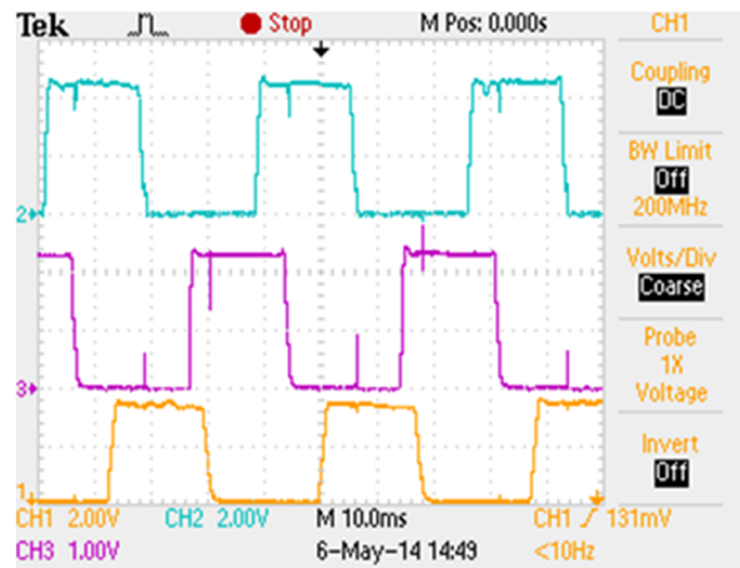

Şekil 18. H21A1 fototransistörden elde edilen tetikleme sinyalleri (The trigger signal is obtained from the phototransistor H21 A1)

Şekil 18'de gösterilen enkoder sinyalleri dikkatlice incelenecek olursa her sargi sirayla enerjilendirilmekte, 150 lik bir dönüş sonrasında bir sonraki sargi da enerjilendirilmektedir.

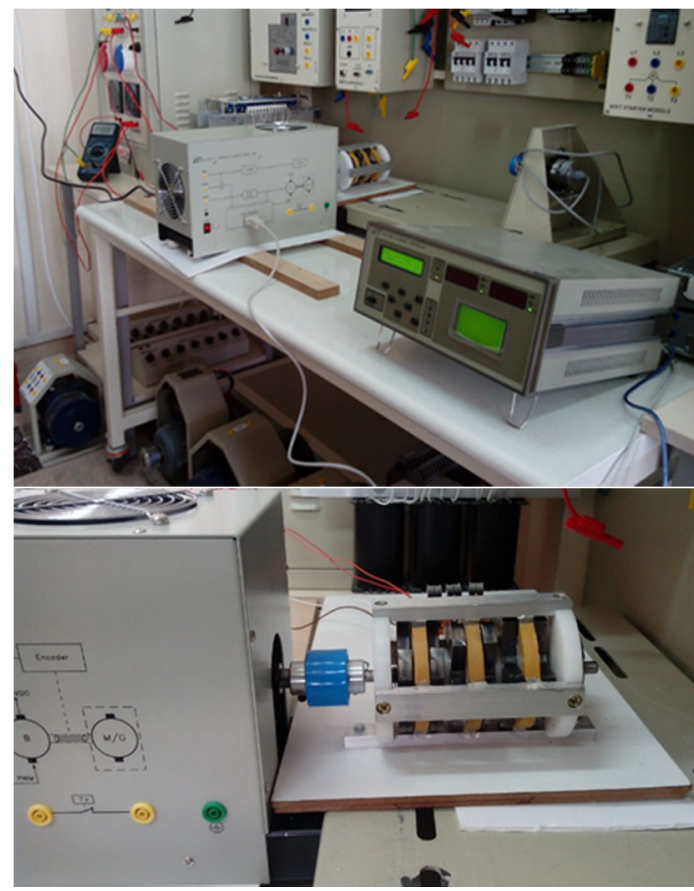

Şekil 19. Deney düzeneği (Experimental setup)

Şekil 19'da EA-ARM'nin deney düzeneği gösterilmiştir. Motorun çalışması sırasında motor faz akımları akım probu kullanılarak ölçülmüştür. Elde edilen faz akımı eğrisi Şekil 20'de verilmiştir. Ölçüm yapıldığı anda akım probu kademesi $100 \mathrm{mV} / \mathrm{A}$ kademesindedir ve bobinlere $48 \mathrm{~V}$ gerilim uygulanmıştır. Bobine uygulanan enerji kesildikten sonra, faz bobini üzerinde biriken enerjinin sönümlenme süresinin oldukça uzun olduğu Şekil 20'den anlaşılmaktadır. Uzun sönümlenme süresi motorun negatif tork üretmesine sebep olmaktadır. Dolayısıyla motor torkunun azalmasına sebep olmaktadır. $\mathrm{Bu}$ durum sürücü kabiliyetlerinin düzeltilmesi ile önlenebilir.
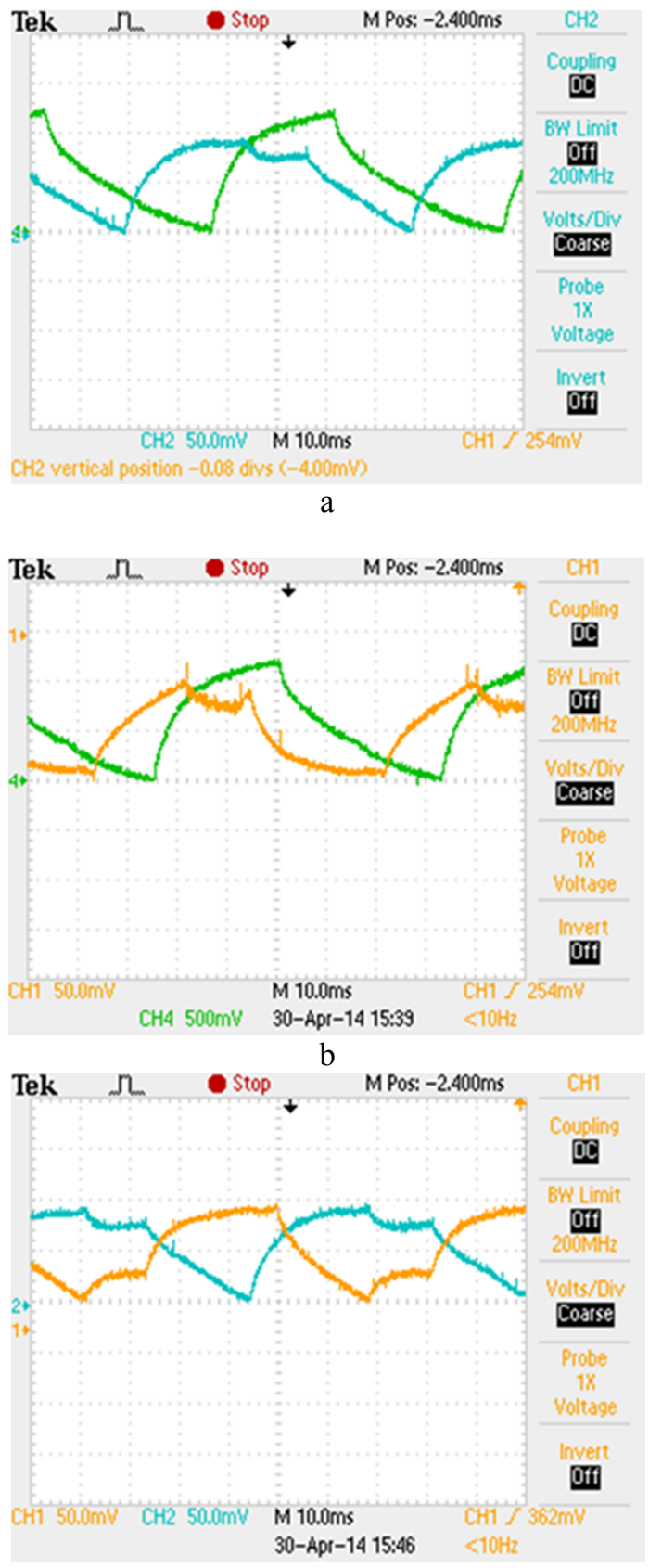

c

Şekil 20. Motor sargılarının akım eğrileri a) A ve B sarg1 akımları, b) B ve C sarg1 akımları, c) $\mathrm{C}$ ve A sarg1 akımlar1 (Curves of the motor coil current a ) A and B winding currents, b) $\mathrm{B}$ and $\mathrm{C}$ winding currents, c) $\mathrm{C}$ and $\mathrm{A}$ winding currents)

Şekil 19'da gösterilen deney düzeneğinde EAARM'nin miline akuple bir fren mekanizması 
bağlanmış ve tork ölçümlerinin yapılması sağlanmıştır. Fren ve tork ölçüm ünitesi K\&H MFG firmasının EM-3320-1N fren kontrol ünitesi ve EM3320-1C manyetik toz fren ünitelerinden oluşmaktadır. Yapılan deneyler sonucunda EAARM'nin tork değeri ölçülmüş ve simülasyon sonuçları ile karşılaştırılmıştır. Şekil 21 ve Şekil 22'de tork ölçüm değeri ve karşılaştırmalar gösterilmiştir.

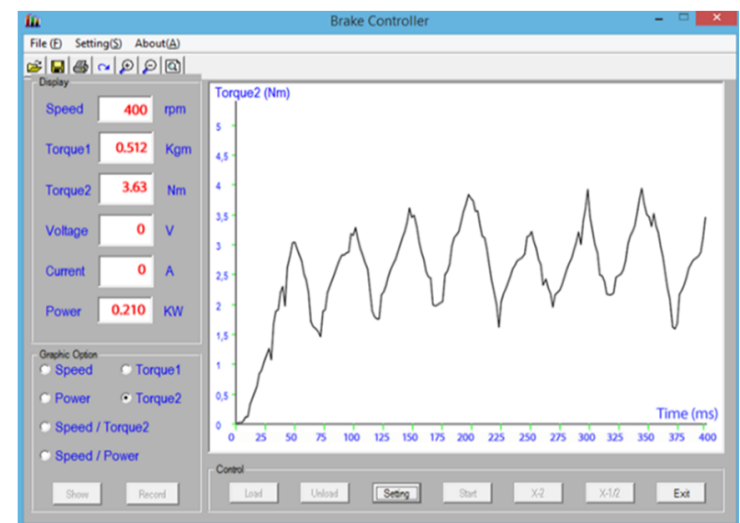

Şekil 21. K\&H MFG şirketinin fren kontrol ünitesi bilgisayar ara yüzünden ölçülen tork eğrisi (K \& H MFG company torque curve measured from the brake control computer interface)

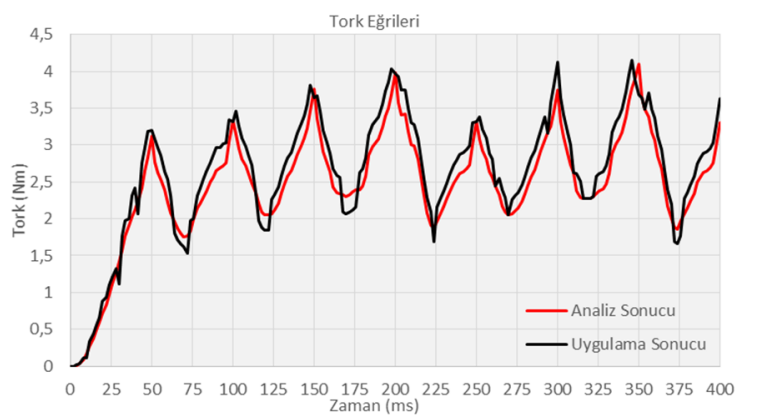

Şekil 22. EA-ARM'un tork-zaman eğrisi (AF-SRM's torque-time curve)

Ölçüm sonuçları ve simülasyon sonuçları tek bir grafikte gösterildiğinde sonuçların birbirine yakın değerler verdiği anlaşılmaktadır.

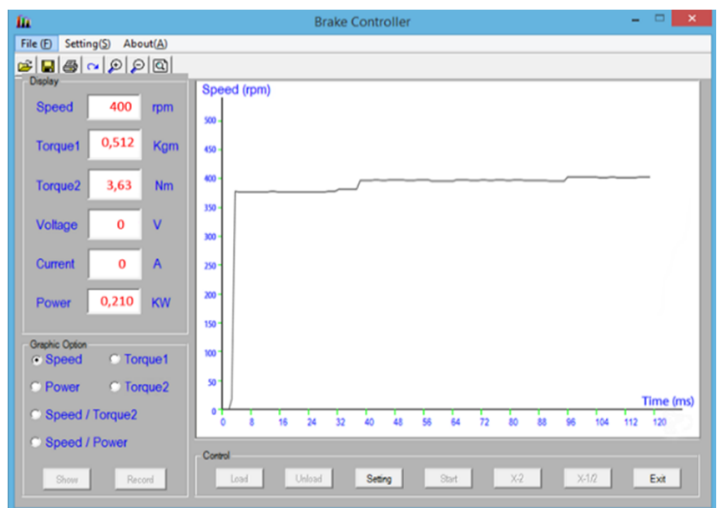

Şekil 23. EA-ARM'un Hız-zaman eğrisi (AF-SRM's speed-time curve )
EA-ARM'nin hız-zaman grafiği de aynı deney düzeneğinde ölçülmüş ve simülasyon sonuçlarına yakın hızlarda döndüğü görülmüştür. Şekil 23'de ölçüm düzeneğinin ara yüzünden alınan hız-zaman grafiği gösterilmiştir.

\section{SONUÇLAR (CONCLUSIONS)}

Günümüzde anahtarlamalı relüktans motorların tasarım ve uygulamasına yönelik birçok araştırma ve çalışma gerçekleştirilmektedir. Yapılan çalışmalar incelendiğinde akademik düzeydeki bu çalışmaların motorun yapisal tasarımı ve kontrol devresinin tasarımı üzerine yapıldığ 1 sonucuna varılabilir.

Gerçekleştirilen bu çalışma ile de yeni bir anahtarlamalı Relüktans Motor yapısı ortaya konmuştur. Yapılan çalışmayı geleneksel ARM yapısından ayıran özellikleri, faz sargılarının mil eksenine dik oluşu, rotor kutuplarının stator kutupları ile değil de motor gövdesi ile sınırlanması ve statorun parçalı yapısı ve rotor içine gömülü oluşudur.

Tasarımda tork kolu uzunluğu mümkün olan en büyük değere çıkarılmıştır. Tasarlanan motorun eksenel akılı ARM sınıfına girmesi ve rotor yapısının her faz için ayrı katmandan oluşması sebebiyle çalışma, Eksenel Akılı Anahtarlamalı relüktans Motor olarak adlandırılmıştır.

Tasarımı yapılan EA-ARM yapısı Ansoft Maxwell 3D programı ile modellenmiştir. Rotor zamana göre tranzient analizleri yapılmış tork, faz indüktansı ve manyetik akı yoğunluğu değerleri elde edilmiştir. Tasarımı yapılan EA-ARM yapısı fiziksel olarak da gerçeklenmiş ve tasarımın uygulanabilirliği doğrulanmıştır.

Elde edilen tork grafiğinin, ARM tork karakteristiğinde olduğu ve torkta dalgalanmanın meydana geldiği gözlenmiştir. Tork dalgalanmalarının önüne geçmek için fazların belirli konumlarda beraber anahtarlanması önerilmektedir. Motorun faz sayısı arttırılarak dalgalanmaların daha da azaltılması mümkündür.

Tasarımın optimizasyonunun gerçekleştirilerek elde edilen prototipin daha yetenekli bir sürücü ile kontrol edilmesi EA-ARM tasarımının yeteneklerinin ortaya konmasında faydalı olacaktır. Motor prototipi imal edilirken kullanılan steel 1010 malzeme yerine lamine edilmiş ince sac kullanılması motor kayıplarının azaltılması açısından önemlidir.

İleriki çalışmalarda EA-ARM yapısına benzer bir dış rotorlu motor çalışması üzerinde durmak faydalı sonuçlar verebilir. Elektrikli bisiklet ve golf araçlarında bu tasarımın kullanılması denenebilir. 


\section{KAYNAKLAR (REFERENCES)}

1. Irwin, J. D., "Switched Reluctance Motor Drives; Modeling, Simulation, Analysis, Design, and Applications", Series Editor, Auburn University, Alabama, A.B.D., 2001.

2. Vijayraghavan, P., "Design of Switched Reluctance Motors and Development of a Universal Controller for Switched Reluctance and Permanent Magnet Brushless DC Motor Drives", Doktora Tezi, Faculty of the Virginia Polytechnic Institute and State University, Blacksburg, Virginia, 2001.

3. Miller, T.J.E., "Switched Reluctance Motors and their Control", Magna Physics Publishing and Clarendon Press, Oxford, İngiltere, 1993.

4. Nasar, S.A., "DC Switched Reluctance Motor", Proc. IEE, Cilt 116, No 6, 1048-1049, 1969.

5. Lawrenson, P.J., Stephenson, J.M., Blenkinsop, P.T., Corda, J. and Fulton, N.N., "Variable-speed Switched Reluctance Motors", Proc. IEE, Cilt 127, No 4, 253-265, 1980.

6. Byrne, J. and Lacy, J.C.; "Electrodynamic system comprising a variable reluctance machine", U.S. Patent 3956678, May 1976.

7. Üstkoyuncu N., "Anahtarlamalı Relüktans Motorlarda Torkun Kontrolü ve İyileştirilmesi”, Yüksek Lisans Tezi, Erciyes Üniversitesi, Fen Bilimleri Enstitüsü, Kayseri, 2004.

8. Stephenson, J. C., "Computation of Torque and Current in Doubly Salient Reluctance Motors From Non-Linear Magnetization Data", IEE Proceedings Electric Power Applications, Cilt 126, 393-396, 1979.

9. Ray W.F,. Davis RM, Lamson RJ., Stephenson J.M., Fulton N.N. and Blake R.J., "Switched reluctance motor drives for rail traction: a second view" IEE Proceedings Pt.B, Cilt 131, No 5, 220-225, Eylül 1984.

10. Tohumcu M., Ertan H.B.; "Prediction of performance of swithched reluctance motor for design purposes", International Conference on Electrical Machines, Cilt 2, 557-561, Pisa, Italy, 1988.

11. Miller T. J. E., "Electronic Control of Switched Reluctance Machines", Oxford, İngiltere, 48-56, 2001.

12. Miles A.R.,"Design of a $5 \mathrm{MW}, 9000 \mathrm{~V}$ Switched Reluctance Motor", IEEE Trans. Energy Conversion, Cilt 6, 484-491, 1991.

13. Khwaja M. R., "Advantages of Switched Reluctance Motor Applications to EV and HEV: Design and Control Issues", IEEE Transactions on Industrial Applications, Cilt 36, No 1, 1-4, 2000.

14. Ohdachi, Y., Kawase, Y., Miura, Y., Hayashi, Y., "Optimum design of switched reluctance motors using dynamic finite element analysis", IEEE Transactions on Magnetics, Cilt 33, 2033-2036, 1997.
15. Fahimi, B., Suresh, G., Mahdavi, J., Ehsami, M., "A new approach to model switched reluctance motor drive application to dynamic performance prediction, control and design", 29th Annual IEEE Power Electronics Specialists Conference, Fukuoka, Japonya, Cilt 2, 20972102, Mayıs 1998.

16. Matsui, N., Kosaka, T., Minoshima, N., Ohdachi, Y., "Development of SRM for spindle motor system", IEEE Industry Applications Conference, Thirty-Third IAS Annual Meeting, St. Louis, Missouri, A.B.D., Cilt 1, 580-585, Ekim 1998.

17. Lee, B.S., Bae, H.K., Vijayraghavan, P., Krishnan, R., "Design of a linear switched reluctance machine", IEEE Industry Applications Conference, Arizona, A.B.D., 2267-2274, Ekim 1999.

18. Fahimi, B., Suresh, G., Ehsani, M., "Large switched reluctance machines: a 1 MW case study", Electric Machines and Drives International Conference IEMD '99, Seattle, A.B.D., 84-86, Mayıs 1999.

19. Sanada, M.. Morimoto, S., Takeda, Y., Matsui, N., "Novel rotor pole design of switched reluctance motors to reduce the acoustic noise", Industry Applications Conference, Conference Record IEEE, 107-113, Ekim 2000.

20. Rahman, K.M., Fahimi, B., Suresh, G., Rajarathnam, A.V., Ehsani, M., "Advantages of switched reluctance motor applications to EV and HEV: design and control issues", IEEE Transactions on Industry Applications, 111$121,2000$.

21. Hall, E. M., Ramamurthy, S.S., Balda, J.C., "Analysis, Dimensional Sizing, and Configuration Comparison of Switched Reluctance Motors Operating under Multiphase Excitation", IEEE Power Engineering Review, Cilt 22, 48-49, 2002.

22. Jiang, Q., Bi, C., Low, T.S., "Numerical design and analysis of switched reluctance motors", The Fourth International Conference on Computation in Electromagnetics, 2002.

23. Hall, E.M., Ramamurthy, S.S., Balda, J.C., "Analysis, dimensional sizing and configuration comparison of switched-reluctance motors operating under multiphase excitation", IEEE Transactions on Energy Conversion, Cilt 17, 325-331, 2002.

24. Mingyao L., Ming C., Zhou E., "Design and performance analysis of new 12/8-pole doubly salient permanent-magnet motor", Sixth International Conference on Electrical Machines and Systems, Beijing, China, 21-25, Kasim 2003.

25. Rizk, J., Nagrial, M.H., Hellany, A., "Design and performance of switched reluctance motors", ICEMS 2003 Sixth International Conference 
on Electrical Machines and Systems, Beijing, China 211-216, Kasim 2003.

26. Higuchi, T., Fiedler, J.O., De Doncker, R.W., "On the design of a single-phase switched reluctance motor", IEEE International Electric Machines and Drives Conference, Wisconsin A.B.D., 561-567, Haziran 2003.

27. Long, S.A., Schofield, N., Howe, D., Piron, M., McClelland, M., "Design of a switched reluctance machine for extended speed operation", IEEE IEMDC'03. International Electric Machines and Drives Conference, Wisconsin A.B.D., 235-240, Haziran 2003.

28. Hur, J., Kang, G.H., Lee, J.Y., Hong, J.P., Lee, B.K., "Design and optimization of high torque, low ripple switched reluctance motor with flux barrier for direct drive", IEEE Industry Applications Conference, 39th IAS Annual Meeting, Seattle, A.B.D., 401-408, Ekim 2004.

29. Lee J.W., Kim H.S., Kwon B.I., Kim B.T., "New rotor shape design for minimum torque ripple of SRM using FEM", IEEE Transactions on Magnetics, Cilt 40, 754-757, 2004.

30. Khor M.T., Sotudeh, R., Lee, D., "Switched reluctance motor based on short flux path control method", 39th International Universities Power Engineering Conference, Bristol, İngiltere, 559562, Eylül 2004.

31. Lee J.H., Lee E.W., Kim J.H., "Design of the single phase SRM for the blower considering self-starting", Proceedings of the Eighth International Conference on Electrical Machines and Systems, Nanjing, China, 667670, Eylül 2005.

32. Mao S.H., Tsai M.C., "A novel switched reluctance motor with C-core stators", IEEE Transactions on Magnetics, Cilt 41, 4413-4420, 2005.

33. Momen, M.F., Husain, I., "Design and performance analysis of a switched reluctance motor for low duty cycle operation", IEEE Transactions on Industry Applications, Cilt 41, 1612-1618, 2005.

34. Khor, M.T., Sotudeh, R., "A 3-phase 12/10 asymmetrical switched reluctance motor", European Conference on Power Electronics and Applications, Dresden, Almanya, 1-9, Eylül 2005.

35. Oh J.H., Kwon B.I., "New rotor shape design of SRM to reduce the torque ripple and improve the output power", Proceedings of the Eighth International Conference on Electrical Machines and Systems, Nanjing, China, 652654, Eylül 2005.

36. Pandey, K., Rajagopal, K.R., "Novel pole shapes for improved performance of switched reluctance hub motors", Intermag IEEE International Magnetics Conference, Nagoya, Japonya, 749750, Nisan 2005.
37. Edrington, C.S., Krishnamurthy, M., Fahimi, B., "Bipolar Switched Reluctance Machines: A Novel Solution for Automotive Applications", IEEE Transactions on Vehicular Technology, Cilt 54, 795-808, 2005.

38. Ashok, P., Tesar, D., "Computer Aided Design of Switched Reluctance Motors for Use in Robotic Actuators", World Automation Congress, WAC, Budapeşte, Macaristan, 1-7, Temmuz 2006.

39. Ohyama, K., Nashed, M.N.F., Aso, K., Fujii, H., Uehara, H., "Design using Finite Element Analysis of Switched Reluctance Motor for Electric Vehicle", 2nd Information and Communication Technologies - ICTTA '06, Damascus, Suriye, 727-732, Nisan 2006.

40. Fujishiro, S., Ishikawa, K., Kikuchi, S., Nakamura, K., Ichinokura, O., "Design of outerrotor-type multipolar switched reluctance motor for electric vehicle", Journal of Applied Physics, Cilt 99, 08R324 - 08R324-3 2006.

41. Cakir, K., Sabanovic, A., "In-wheel motor design for electric vehicles", 9th IEEE International Workshop on Advanced Motion Control, İstanbul, Türkiye, 613-618, 2006.

42. Kachapornkul, S., Jitkreeyarn, P., Somsiri, P., Tungpimolrut, K., Chiba, A., Fukao, T., "A design of $15 \mathrm{~kW}$ switched reluctance motor for electric vehicle applications", ICEMS International Conference on Electrical Machines and Systems, Seoul, Korea, 16901693, Ekim 2007.

43. Oh. S.G., Krishnan, R., "Two-Phase SRM With Flux-Reversal-Free Stator: Concept, Analysis, Design, and Experimental Verification", IEEE Transactions on Industry Applications, Cilt 43, 1247-1257, 2007.

44. Lee C., Krishnan, R., Lobo, N.S., "Novel Twophase Switched Reluctance Machine using Common-Pole E-Core Structure: Concept, Analysis, and Experimental Verification", IEEE Industry Applications Conference, 42nd IAS Annual Meeting, Louisiana, A.B.D., Eylül 2210-2217, 2007.

45. Ekram, S., Ravi, N., Rajagopal, K.R., Mahajan, D., "Design and Development of a High Efficiency Switched Reluctance Motor for a Mixer-Grinder Application", IECON IEEE Industrial Electronics Society, Taipei, Taiwan, 193-197, Kasim 2007.

46. Desai, P.C., Krishnamurthy, M., Schofield, N., Emadi, A., "Novel Switched Reluctance Machine Configuration With Higher Number of Rotor Poles Than Stator Poles: Concept to Implementation", IEEE Transactions on Industrial Electronics, Cilt 57, 649-659, 2010.

47. Ruba, M., Bentia, I., Szabo, L., "Novel modular switched reluctance machine for safety-critical applications", $\mathbf{2 0 1 0}$ XIX International 
Conference on Electrical Machines (ICEM), Roma, İtalya, 1-6, Eylül 2010.

48. Labak, A., Kar, N.C., "Development and analysis of a five-phase pancake shaped switched reluctance motor", XIX International Conference on Electrical Machines (ICEM), Roma, İtalya, 1-6, Eylül 2010.

49. Fenercioğlu, A., "Helisel Yapılı Anahtarlamalı Relüktans Motorun (HY-ARM) Tasarımı ve Analizi" Doktora Tezi, Gazi Üniversitesi Fen Bilimleri Enstitüsü, Ankara, 2006.

50. Hossein T., Ebrahim A., and Mohammad S.T., "New Double-Layer-per-Phase Isolated Switched Reluctance Motor: Concept, Numerical Analysis, and Experimental Confirmation" IEEE
Transactions on Industrial Electronics, Cilt 59, No 2, 830-838, 2012.

51. Sefa, İ., Sliding Mode Yaklaşımı ile Anahtarlamalı Relüktans Motorun Hiz Kontrolü, Doktora Tezi, Erciyes Üniversitesi Fen Bilimleri Enstitüsü, Kayseri, 1997.

52. Hamayer, K., Belmans, R., Numerical Modelling and Design of Electrical Machines and Devices, Wit Press Boston, A.B.D., 1999.

53. Bastos, J.P.A., Electromagnetic Modeling by Finite Element Methods, Marcel Dekker, New York, A.B.D., 2003.

54. Jianning, J., The Finite Element Method in Electromagnetics, John Wiley\&Sons Inc., New York, A.B.D., 1993. 